\title{
From Medication to Meditation: A Critical Disability Studies Analysis of Mindfulness-Based Practices for Children With Learning Disabilities
}

\author{
Emma Peddigrew $^{1} \&$ John McNamara ${ }^{1}$ \\ ${ }^{1}$ Brock University, Canada \\ Correspondence: Emma Peddigrew, Brock University, Canada.
}

Received: August 26, 2019

Accepted: September 24, 2019

Online Published: December 9, 2019

doi:10.20849/jed.v3i3.623

URL: https://doi.org/10.20849/jed.v3i3.623

\begin{abstract}
Learning disabilities (LD) are a widespread phenomenon, affecting many individuals across the globe. Throughout the past 70 years, the field of LDs has aimed to support children, youth, as well as their families, to generate definitions, understand neurological contributions and create meaningful policies and practices. However, despite decades of research, an emphasis on early identification and prevention, and significant policy documents, children and youth with LDs continue to face equally as important difficulties related to one's social and emotional well-being. Critical disability studies (CDS) identifies how political, educational, and social contexts serve as sites for (in)justice (Shildrick, 2007). A CDS framework aims to resist the emphasis of individual impairment and deficiency while incorporating the interests and voices of the individuals with disabilities themselves. Few studies have analyzed the impact of mindfulness on how children with LDs cope with stress, 'failure', and understand their bodies. As a result, this paper will ask: how can mindfulness-based practices be used as a tool to improve the overall well-being of children and youth with a LD? With support from CDS and the utilization of mindfulness-based practices, children and youth with LDs can become connected to the body and mind. This study will enable future research on the importance of self-advocacy, coping, confidence, attention, and emotional regulation for children with LDs. It is through these liberating frameworks that children with LDs can become emancipated from political, historic, social, and cultural constraints.
\end{abstract}

Keywords: learning disabilities, critical disability studies, mindfulness, mindfulness-based practices, children, youth, well-being

\section{Introduction}

We live in a world where children and youth experience extraordinary levels of stress (Bauza, Barnes, \& Treiber, 2003; Fisher, 2006). This stress has the ability to develop into depression, anxiety, anger, loneliness and a decreased self-esteem and self-confidence (Bauza et al., 2003; Fisher, 2006; Mendelson et al., 2010; Rempel, 2012). Due to social constructions, individuals with disabilities may be more inclined to internalize negative feelings, resulting in a greater impact to one's overall learning and well-being. Learning disabilities (LD) derive from neurological differences in brain structure and function, affecting an individual's ability to grasp, process, communicate and retrieve information (Cortiella \& Horowitz, 2014). Typically, LD research has taken a deficit approach, which emphasizes a child's disabilities and fails to consider one's abilities. The implications of deficit research call for interventions aimed at redefining what constitutes 'success' and consequently, 'failure.' Critical disability studies (CDS) works to deconstruct this deficit model paradigm by acknowledging the impact of one's environment. Mindfulness can aid in the development of self-empowerment for children with LDs who are often underestimated. Mindfulness refers to the process of continuous awareness and attention toward present-moment experiences with a nonjudgmental point of view (Rempel, 2012). Mindfulness involves deliberately observing and accepting what is currently happening in our mind, body, and environment (Huppert \& Johnson, 2010). Mindfulness shifts attention from being focused on anything outside of the present moment, including plans, fantasies, memories, or worries (Brown \& Ryan, 2003; Nagy \& Baer, 2017).

Few studies have analyzed the impact of mindfulness on how children with LDs cope with stress, 'failure', and understand their bodies. As a result, this paper will ask: how can mindfulness-based practices be used as a tool to improve the overall well-being of children and youth with a LD? With the utilization of a CDS framework, 
mindfulness will offer techniques to shift our understanding of individuals with LDs from the traditional deficit model paradigm to a more strengths based approach. The aim of the present paper is to fill this gap by exploring how a CDS framework provides unique ways of analyzing traditional constructions of disability. Mindfulness-based practices work to empower and liberate one's body and mind, serving as an anchor to individuals with a LD. Individuals will be provided with the tools, independence, and confidence to revert the epidemic of over-diagnosis and (remove word traditional) medicalization to one of meditation and mindfulness.

\section{Method}

\subsection{Theoretical Framework}

In 1980, the World Health Organization [WHO] published the Classification of Impairment, Disability and Handicaps. Within this document, disability was defined as the 'lack of ability to perform an activity in a manner that is considered normal for a human being' (Cameron, 2014, p. 99). Impairment was viewed as a social progress threat and people with severe impairments were perceived as mutants (Radford, 1994). This classification was accepted by many, becoming the sole image of disability. Historically, society has understood individuals with disabilities from a medical or deficit model, which labels individuals as dysfunctional and in desperate need of treatment (Peña, Stapleton, \& Schaffer, 2016). According to Reddy (2011) disability was defined as a disadvantage or deficiency that limits normal achievements with predominant physical or psychological medical significance. The 'medicalization' of disability made human variation an abnormality from the norm, as a deficit, a pathological condition, and most considerably, as a personal tragedy and individual burden (Reddy, 2011).

Critical disability studies is an interdisciplinary and emancipatory framework that "seeks to extend and productively critique the achievements of working through more modernist paradigms of disability, such as the social constructionist model" (Shildrick, 2007, p. 233). CDS questions how knowledge is constructed in order to maintain structures and systems that exclude and control marginalized populations, such as those with disabilities (Peña et al., 2016). Historically, society has understood individuals with disabilities from a medical or deficit model, labeling individuals as dysfunctional and in desperate need of treatment (Peña et al., 2016). It is important to understand how CDS does not ignore one's individual challenges (Castrodale, 2017), rather it acknowledges one's capabilities to become resilient and shift the traditional view of disability as "at risk" to "having potential." CDS raises questions regarding how information is communicated, accessed, and (re)interpreted and the ways this can (dis)advantage specific individuals (Castrodale, 2017). "Critical disability studies might be viewed then....as a platform through which to think through, act, resist, relate, communicate, and engage with one another against the hybridized forms of oppression and discrimination..." (Goodley, 2012, p. 11). CDS views disability as the place for reconfiguring the relationships and interactions we have with one another (Goodley, Lawthom, Liddiard, \& Runswick-Cole, 2017). Society perpetuates the idea of a 'normal' body, one in which a disabled body differs from. However, a CDS framework understands how 'normal' is a construction, and therefore so is 'disability' and 'impairment.' Thus, one's subjectivities and sense of self is constituted in cultural, political, and social realms (Goodley et al., 2017).

When disabilities are traditionally understood at an individual level, the integration and impact of structural, systematic, and institutional inequalities are ignored. By ignoring the greater issue, an ablest worldview full of stereotypes and prejudices is perpetuated. However, we must be reminded that individuals with disabilities are bound by structural and attitudinal barriers that limit one's capacity to navigate society (Martin, 2012; Peña et al., 2016). This suggests that people with disabilities must work toward an able-bodied norm in order to be seen as productive members of a capitalist society (Goodley \& Runswick-Cole, 2013; Peña et al., 2016). Therefore, disability remains a social issue to be deconstructed by societal change (Goodley, 2001). A CDS framework is crucial for this analysis as the emphasis of individual impairment and deficiency is resisted while incorporating the interests and voices of individuals with disabilities. This framework identifies how political, educational, and social contexts serve as sites for (in)justice (Peña et al., 2016). With this understanding and the utilization of mindfulness-based practices, children with LD can become connected to the body and apply different strategies to problems commonly viewed in a deficit framework. Thus, a CDS framework is crucial in order to eliminate oppression and discrimination (Goodley et al., 2017; Peña et al., 2016). In Kimberlin (2009) review of the literature, contemporary discourses of disability were found to be rooted in a social model, emphasizing social barriers rather than individual's impairments. Both the United Nations Convention on the Rights of Persons with Disabilities (2006) and the International Classification of Functioning, Disability and Health (2001) define disability as the outcome of complex interactions between conditions of health and characteristics of one's social, attitudinal, and physical environment, which can hinder one's successful and full societal participation. 
While taking the nature of disability into consideration, it is imperative to focus on capabilities, in regards to obstacles that inhibit complete and effective empowerment of all citizens, while being proactive to address such barriers (Kimberlin, 2009; Nussbaum, 2003; Sen, 2004). In order for individuals with disabilities to exercise their rights on an equal basis with nondisabled members, barriers such as prejudice, discrimination, and inaccessibility must be addressed (Cobigo \& Stuart, 2010). It is when a CDS framework is utilized that individuals can acknowledge how children with disabilities have the potential to re-design playgrounds, re-think classroom organization, re-engage with school leadership, and shake up the pedagogy (Goodley et al., 2019). To successfully utilize a CDS perspective when analyzing children with LDs, it is essential to first completely understand traditional understandings of LDs and its consequences on one's overall well-being.

\section{Results}

\subsection{Learning Disabilities}

Learning disabilities (LD) are a widespread phenomenon, affecting many individuals across the globe. Approximately $50 \%$ of children identified for special educational services are those with an LD, revealing how LDs constitute the largest field of special education (Büttner \& Hasselhorn, 2011; Cortiella \& Horowitz, 2014; Kavale \& Forness, 2006; Torgesen, 2004). For several decades, the definition of LDs has been an ongoing debate amongst multiple disciplines, including education, medicine, sociology, and psychology (Büttner \& Hasselhorn, 2011; Chan \& Dally, 2000; Mather \& Gregg, 2006, Skues \& Cunningham, 2011). Therefore, LDs have not been uniformly defined due to its variability across social, clinical, research, educational, and political contexts. For instance, both the 2006 Participation and Activity Limitation Survey (Brennan, 2009) and the 2012 Canadian Survey on Disability (Bizier, Till, \& Nicholls, 2015) define a LD as a form of an attention deficit disorder (ADD), attention-deficit/hyperactivity disorder (ADHD), dyslexia, and other developmental disabilities regarding educational skills (D'Intino, 2017). In contrast, the Learning Disabilities Association of Canada [LDAC] does not make any explicit remarks of ADD and ADHD within their definition. (remove the 's' of definitions and 'of LD'). Thus, the LDAC definition has become one of the most widely accepted, which identifies LDs as lifelong, neurobiological, or injury-related brain impairments, impacting either one or more learning related processes (2017).

Traditionally LDs are understood as a disorder in one or more basic psychological processes associated with the utilization of spoken or written language (U.S Congress, 1975). This can manifest itself into an imperfect ability to speak, write, spell, listen, and think (U.S Congress, 1975). Specifically, a LD is concluded to be a presumed left-sided neurological processing issue (Paulesu, Danelli, \& Berlingeri, 2014). Similarly, Sharfi and Rosenblum (2014) define LDs as an umbrella term that includes neurological disorders caused by central nervous system deficits that influence one's ability to process, convey, and sustain knowledge. Likewise, the LDAC includes reference to LDs being a neurobiological disorder primarily affecting one's ability to organize, retain, understand, acquire, and use information (2005). Yet, more recent definitions include qualities apart from neurological explanations and consider multiple domains of one's life. The APA DSM-5 suggests that LD diagnosis should include a more comprehensive clinical synthesis of family, medical, educational, and developmental reports (Cavendish, 2013). The improved inclusive and holistic diagnostic criteria will reflect LDs complicated nature and the importance of comprehensive data on multiple environmental aspects including parenting, self-perceptions, and relationships (Sharfi \& Rosenblum, 2014). Throughout the past 70 years, the field of LDs has aimed to support children, youth, and as well as their families living with LD, to generate definitions, understand neurological contributions and create policies and practices (Cortiella \& Horowitz, 2014; Snow et al., 1998). However, despite decades of research, an emphasis on early identification and prevention, and important policy documents, children and youth with (remove 'a') LDs continue to face equally as important struggles related to mental health, wellness, and self-identity (Cortiella \& Horowitz, 2014).

\subsection{Connection Between Learning Disabilities and Socioemotional Difficulties}

Recently, LDs has been understood as encompassing not only neurological explanations, but social and emotional aspects as well. From as young as eight years old and progressing into adolescence, children and youth with LDs have continuously been recorded higher on inventories measuring depression (Wilson, Armstrong, Furrie, \& Walcot, 2009). The National Center for Learning Disabilities [NCLD] found children with LD being twice as likely to be suspended compared to children and youth without LD (2017). The general population's school dropout rate is $6.5 \%$ compared to children and youth with a LD whose dropout rate was found to be $18.1 \%$ (NCLD, 2017). The National Longitudinal Survey of Children and Youth (2007) reported that $76.1 \%$ of parents of a child without a LD said their child was doing "well" or "very well" at school, compared to only $5 \%$ of parents of children with a LD. Within the same report, individuals with LDs were reported three 
times less likely to report "good" to "excellent" and more likely to report "fair" to "poor" in regards to one's general, physical, and mental health, compared to the general population. These detrimental reports of one's well-being raise concerns for suicide rates amongst individuals with LDs. The National Longitudinal Study of Adolescence Health found that $5.7 \%$ of adolescence living with a LD claimed to have had attempted suicide at least once in their life. These individuals are also more likely to report bullying, peer victimization (Baumeister, Storch, \& Geffken, 2008; Mishna, 2003) and social rejection (Bryan, Burstein \& Ergul, 2004).

Seventy-five percent of children with a LD also demonstrate social skill deficits (Kavale \& Mostert, 2004). Social competence refers to the ability to independently and successfully engage in social interactions, have one's needs and desires met across diverse contexts, and to establish and maintain healthy relationships (Stichter, O'Connor, Herzog, Lierheimer, \& McGhee, 2012). According to Integra's LDMH: A Handbook on Learning Disabilities and Mental Health, social competence is more than having appropriate social skills; but reflects the interconnected and complex set of skills needed to understand social rules and social contexts, reading non-verbal communication, and being able to regulate behaviors and emotions (2016). LDs go beyond academic difficulties and reflect greater social competence challenges in part of the nature of one's information processing challenges (Kavale \& Mostert, 2004). Poor social skills may be a result of deficits within receptive and expressive communication skills, as well as one's socioemotional problem-solving abilities, the surrounding environment, and cognitive processes (Bryan et al., 2004; Buonomo, Fiorilli, Geracia, \& Peped, 2017; Fletcher, Morris, \& Lyon, 2003). Additionally, motivation and emotion can provide environmental explanations for the academic performance of children with a LD (Buonomo et al., 2017; Fletcher et al., 2003).

An important predictor of socioemotional well-being is the ability to interact with social environments, develop reciprocal relationships, and recognize emotions (Gumpel, 2007; Kavale \& Mostert, 2004). Whether one experiences peer acceptance provides an evaluation of social status through popularity, rejection and neglect (Vaughn \& Haager, 1994) and unfortunately for children with LDs peer acceptance is quite minimal (Buonomo et al., 2017). Children with LDs are more likely to exhibit negative self-perceptions, which consequently may reveal life-long implications including poor educational competence, aggression, anxiety, and future resilience difficulties (Gumpel, 2007; Buonomo et al., 2017). Although individuals with LDs may work incredibly hard, the outcomes may not reflect one's effort, resulting in constant experiences of repeated failure (Integra, 2016). With confidence at an all time low, it is common to see behaviors as 'oppositional' or 'non-compliant'. However, these behaviors may reflect an understandable coping strategy of hopelessness or avoidance (Integra, 2016). Children and youth with a LD may feel as if they are letting down parents, peers, and teachers, and not meeting other's expectations (Integra, 2016). This can all lead to experiences of negative feelings, including frustration, sadness, worry, and anger (Integra, 2016). It must be acknowledged that these effects are not bound to children and youth. As individuals with a LD develop into adolescence and adulthood these affects will only intensify. These detrimental long-term effects are pervasive and concerning if overlooked by one's primary reading difficulties, which has traditionally been the only thing associated with LDs. The social construction of what constitutes learning and 'success' fails to correlate with the unique ways children and youth with a LD learn. Thus, mindfulness-based practices can provide alternative approaches to learning and well-being, which encompasses far more than any traditional academic intervention would.

\subsection{Mindfulness}

Mindfulness, in translation to the word sati, essentiality meaning awareness, is originated from Buddhist culture (Ditrich, 2016; Kabat-Zinn, 2003; Nagy \& Baer, 2017). Mindfulness is understood as the protection of the mind, central to the cultivation of nourishing mental states and wisdom (Ditrich, 2016). The Buddhist doctrine regarding suffering increases knowledge and attention capacity, while understanding the wholesome nature of mental and physical processes (Bistagani \& Najafi, 2017; Ditrich, 2016; Nagy \& Baer, 2017). When practiced in the Buddhist culture, mindfulness is more than a tool in one's psychological toolkit but rather a way of being present, understanding the world, and becoming liberated from ignorance (Kabat-Zinn, 2003; Rempel, 2012). Although, this practice of awareness was first introduced in ancient Eastern meditation traditions, recently mindfulness- based practices have been examined and adopted in contemporary Western culture as well.

The 2010 Mental Health Foundation Report refers to mindfulness as a way of paying attention. It means consciously bringing awareness to our experience, in the present moment, and without making judgments. Therefore, mindfulness is opposite of "auto-pilot" or behaving spontaneously, as being mindful supports the idea of becoming nonreactive, nonjudgmental, and compassionate (Geisler, Bechtoldt, Oberlander, \& Schacht-Jablonowsky 2018; Nagy \& Baer, 2017). Put differently, Langer and Moldoveanu (2000) understand mindfulness as the process of drawing on novel distinctions or seeing things for how they truly are. The most prominent definition of mindfulness is made by Kabat-Zinn (2003), which states mindfulness involves "paying 
attention in a particular way: on purpose, in the present moment and non-judgmentally" (p. 4). Similarly, mindfulness is also understood as being conscious and bearing witness to one's personal experiences (Napoli, Krech, \& Holley, 2005; Rempel, 2012). Thus, individuals can pay attention to physical thoughts and one's reaction to them. Commonly, individual's experiences can go unrecognized due to the emphasis on external events, thoughts, interactions, memories or fears. However, when maintaining conscious awareness one can understand things for how 'they truly are' and decide how to respond appropriately (Huppert \& Johnson, 2010).

\subsection{Connection Between Mindfulness and Socioemotional Difficulties}

For many young individuals, childhood encompasses a period of hardships, anxiety, and vulnerability (Fisher, 2006). In a world that is competitive and materialistic, children are bombarded by information. Children find it difficult to articulate personal issues as a result of being prey to the anger and frustration of others (Fisher, 2006). Pressure to perform on exams and tests hold an anxiety of their own. However, for children and youth with a LD, this anxiety is often intensified. Mindfulness is beneficial for children as these self-management techniques play a crucial role in one's developmental trajectory (Rempel, 2012; Semple, Reid, \& Miller, 2005). The ideal psychological state for learning is with a relaxed attention (Fisher, 2006; Claxton, 1997). Mindfulness enables relaxation by focusing on breathing and attention, which opens the brain and prepares the mind for creative learning (Fisher, 2006). Learning requires a balance of articulation and attention (Fisher, 2006), something individuals with a LD are typically assumed to struggle with. If traditional education emphasizes the articulation of one's ideas, other equally as important interactions, such as the focus of attention, are overlooked (Fisher, 2006). Therefore, mindfulness works to practice this attention to words, experiences, and thoughts (Fisher, 2006; Haynes, 2002).

Mindfulness creates potential for improved impulse control, decreased emotional reactivity to unexpected stimuli, and greater self-awareness (Mendelson et al., 2010). Research conducted within hospital settings report a wide range of health benefits, which include reduced stress and blood pressure, drastic mood improvements, and an increase in immune functioning (Fisher, 2006; Murphy \& Donovan, 1999). All factors which benefit one's social and emotional well-being. Mindfulness-based interventions show promise in relieving stress by improving social-emotional development, self-regulation, and temperament (Mendelson et al., 2010; Rempel, 2012). Mindfulness training can enhance relationships, self-confidence, attention, and reduce stress (Fisher, 2006; Rempel, 2012; Kabat-Zinn, 2003). Through breath awareness and 'following the breath' the mind can become still, focused, and calm (Fisher, 2006). By focusing on the breath, individuals will be able to access ignored details of past experiences stored in both the body and mind and recognize details of current experiences that are registered subconsciously (Fisher, 2006). Therefore, individuals will be able to use mindfulness techniques, such as breath awareness, to aid in study, sleep, or calm themselves during times of stress both academically and socially (Fisher, 2006).

Mindfulness works to expand aspects of metacognitive awareness and 'me-cognition', which refers to what an individual thinks and knows about themselves in the privacy of one's own thoughts (Fisher, 2006). This nonjudgmental attention and focus on moment-to-moment experiences can increase one's cognitive functioning, psychological well-being, and resilience (Brown \& Ryan, 2003; Semple et al., 2005; Geisler et al., 2018). The practice of controlling the mind to overcome waves of distracting or negative thoughts, allows individuals to become 'centered' - fully conscious of one's entire being, not just within one's own thoughts and feelings (Fisher, 2006; Mendelson et al., 2010). It is when individuals are able to broaden one's perspective and see beyond their personal frame of reference that development occurs (Rempel, 2012; Shapiro, Carlson, Astin, Freedman, 2006;). In sum, mindfulness practices has been shown to improve emotion regulation (Nagy \& Baer, 2017; Robins, Keng, Ekblad, \& Brantley, 2012), attention capacities and working memory (Mrazek, Franklin, Phillips, Baird, \& Schooler, 2013; Nagy \& Baer, 2017), and reduce rumination (Rempel, 2012; Fisher, 2006; Kabat-Zinn, 2003). Educators, researchers, mental health professionals, and others are becoming increasingly interested in supporting the 'whole' child (Rempel, 2012). Mindfulness practices work to do just that. Mindfulness aims to develop the emotional intelligence of individuals, while not solely focusing on academics (Rempel, 2012). Through mindfulness-based practices, the necessary factors for a positive socioemotional well-being such as creativity, empathy, compassion for the self and others, and prosocial relationships can be enhanced (Fisher 2006; Mendelson et al., 2010; Nagy \& Baer, 2017; Rempel, 2012).

\section{Discussion}

The number of children diagnosed with mental health disorders, including anxiety and depression, is steadily increasing (Hayes, Bach, \& Boyd, 2010; Kashani \& Orvaschel, 1988; Rempel, 2012). The prolonged anxiety, chronic stress, and depression associated with LDs can result in negative brain changes such as loss of retraction 
of dendrites and synapses that ultimately effect long term-cognitive functioning (Scruton \& McNamara, 2014). Academic and social skill programs are continuously aimed at improving the success rates of children with LD. However, these children are still suffering in a profound way, exhibiting a significant gap in knowledge production. Do individuals believe children with LDs are incompetent and unable to practice mindfulness? Is this assumption rooted from the traditional construction of disability being solely understood as a deficit? When children are unable to cope with mental health concerns, the ability to disregard negative stimuli is inhibited, resulting in a decreased ability to succeed (Rempel, 2012). Yet, more specifically, the question of how a CDS lens coincides with practices of mindfulness is imperative in order to part from the deficit understanding of disability. Although one may have the capacity to be mindful, a state of mindfulness requires effort, as one must disregard the instinctive feeling to judge and react to a current external and internal situation (Geisler et al., 2018). Calming the mind and being present enhances both positive feelings and functioning (Huppert \& Johnson, 2010). Commonly, children with LDs have been seen as incapable of self-empowered thinking. However, mindfulness allows for practices that debunk these traditional ways of thinking by enabling views of children with a LD as capable, interconnected, and in control. This promising longitudinal approach to social and emotional well-being is critical for a child's successful development.

CDS is interested in deconstructing what constitutes 'normal' and how these constructions are built upon social, political and cultural structures (Goodley et al., 2017). Children with LDs are constantly been failed, as one's disability is exclusively understood as a deficit to one's ability to succeed. However, a CDS lens views 'success' as rhetoric, and how this perpetuates the myth of independency and ableism (Karmiris, 2016). The construction of 'normal' therefore goes hand-in-hand with the construction of 'success' and 'failure.' Society has constructed the idea that in order to be successful one must be independent and by obtaining help from others characters you as a failure. Therefore, for children with LDs, who already fall outside of 'normal' constraints, one's success is unconsciously already a failure (Karmiris, 2016). By encouraging children with LDs that success and normal are correlated and thus either praise or discipline individuals for this, the construction is perpetuated. Therefore, society must begin viewing failure as a form of resistance and refuse the limits of what constitutes success (Karmiris, 2016). These children must not be discounted, but instead require self-discovery to find unique ways of navigating society (Karmiris, 2016). Mindfulness-based practices can aid in self-discovery, by enabling children with a LD to cultivate new connections with one's feelings and thoughts, not only at one's present stage of life, but within the future. In turn, this relationship individuals to act more purposefully and engage in valuable activities, despite unpleasant feelings and thoughts being present (Nagy \& Baer, 2017).

Traditionally, individuals with disabilities have been viewed as hopeless, incompetent and dependent on others. CDS encompasses an understanding of LDs as a social, political, cultural, relational, historical and discursive phenomenon, rather than being solely based on individuals 'naturalized impairment' (Goodley, 2001). Therefore, by implementing mindfulness tactics, children with disabilities and the overall society, can begin to understand the importance of multiple perspectives and embrace the realization that one optimal perspective is unrealistic (Rempel, 2012). The constant overload of images, information, rules, and expectations, can bombard and challenge a child's thinking capacity, making learning increasingly more difficult (Fisher, 2006; Rempel, 2012). For children who have previously been told they have a LD, these stressors can increase the risk of negative outcomes. Mindfulness-based practices value the development of prosocial relationships, compassion for the self and others, empathy, and creativity (Rempel, 2012), all of which the traditional deficit model views children with a LD being unable to achieve. By advocating for mindfulness practices, children with LDs will begin to feel in control of one's own developmental path and overall well-being.

Historically, the disabled body has been understood as the body of being - one in which history has shaped in relation to feelings of grief, guilt, and loss (Goodley \& Runswick-Cole, 2013). This is the body that is in dying need of medication and intervention in order to mask differences and become integrated into a normative society (Goodley et al., 2017). Referring back to the previous definition of LDs made by the U.S Congress in 1975, a LD is considered the imperfect ability to speak, write, spell, listen, and think. Within this definition, it can be viewed how traditional negative constructions of disability also correspond with constructions of perfection. A CDS framework shapes the disabled body as one of possibility, this is the body that is becoming - one in which is emancipated from complex environmentally bound forces (Goodley \& Runswick-Cole, 2013). This body that is becoming shifts the support for children with disabilities from medication to meditation. Mindfulness offers life-long practices for children with LDs that challenge negative constructions of the disabled body being one that is unable to regulate emotions, build relationships, and become a self-advocate.

A child's most important system of support is one's family. Mindfulness has the ability to improve parents' and caregiver's perceptions of their children's LD as well. These children may feel unsuccessful in any realm of 
academia or social settings and thus fear parental neglect, similar to the peer neglect previously being faced in greater society. When parents have a child with a LD, they are bombarded with reports and a diagnosis criterion regarding the circumstances a child will constantly struggle with. Mindful parenting involves paying attention to the child and one's parenting style in a specific way (Kabat-Zinn, 2003). Parents can adopt the understanding of disability from CDS in order to resist preconceived future trajectories and empowering these children to reject negative connotations. Within mindfulness-based parenting, caregivers will be able to understand how to pay attention to a child non-judgmentally, reduce automatic (negative) reactions and increase present moment awareness (Kabat-Zinn, 2003). As a result of one's parents/caregivers being able to practice mindfulness, a child with a LD will be able to understand how traditional views of one's 'inability to succeed' is being challenged. Additionally, these children will internalize the support and confidence given from one's support system and be encouraged to develop into self-proclaimed disability advocates.

Mindfulness-based practices may also enable children with LDs and other disabilities to exercise a CDS mentality. A CDS framework provides practices and tools to discard society's interventions that traditionally place limits on one's potential, capacities, and possibilities. The tools of mindfulness, will not only reduce stress, anxiety and depression, but will assist children with LDs, and all disabilities, on an emotional, social, and individual level to resist oppression, discrimination, and stereotypes placed upon them from an ableist society. It is through the practice of mindfulness and the association of a CDS framework that the body and mind will be liberated rather than seen as a prison. Children with LDs will become inspired to question the notion of disability and the constraints of one's diagnosis. Mindfulness offers tools to challenge traditional discourses of perfection, ability, normal, and success. A CDS framework will enable mindfulness-based practices to be understood as the acceptance of one's body and mind while breaking through the traditional deficit discourse of disability.

LDs are not a prescription for failure (Castrodale, 2017). Social structures, relationships, and practices constantly naturalize the subjectivities of people with learning disabilities. Society ultimately creates disablement and acts as the mediator of disciplinary powers that (re)produce understandings of different minds and bodies (Goodley, 2001). A CDS framework constructs perceptions in a specific way that undermines what appears obvious and natural (Goodley, 2001). With the implementation of mindfulness, traditional negative constructions of children with disabilities can be reestablished. Mindfulness practices offer lifelong skills that empower children and youth throughout one's entire life (Rempel, 2012). This analysis may have been made stronger by elaborating and encompassing the specific mindfulness techniques such as body scans, meditation, and yoga as well as including more tangible results from mindfulness-based programs. This analysis provides opportunities to unique ways of learning and alternative approaches to supporting children with LDs, by concentrating on the present moment and controlling attention. Mindfulness and CDS can do just that by focusing on the environment surrounding an individual and one's inherent strengths. By critiquing the construction of "disability" and the associated stigma, mindfulness can shift the traditional understanding of children with LDs being seen as unsuccessful and incapable of self-empowerment to a more holistic world view that challenges political and social ways of being. The study of mindfulness through a CDS framework will enable future research on the importance of self-advocacy, coping, confidence, attention, and emotional regulation for children with LDs. It is through these frameworks that children with all disabilities can become emancipated from political, historic, social, and cultural constraints.

\section{Acknowledgements}

The authors would like to acknowledge the Social Sciences and Humanities Research Council [SSHRC] for funding this study.

\section{References}

Baumeister, E. A., Storch, E., \& Geffken, G. (2008). Peer victimization in children with learning disabilities. Child \& Adolescent Social Work Journal, 25(1), 11-23.

Bauza, L., Barnes, V., \& Treiber, F. (2003). Impact of stress reduction on negative school behavior in adolescents. Health and Quality of Life Outcomes, 1(10), 1-10.

Bistagani, M. G., \& Najafi, F. M. (2017). Effectiveness of child-centered mindfulness on social skills and self-efficacy of children with learning disabilities. Social Behavior Research \& Health, 1(2), 91-99.

Bizier, C., Till, M., \& Nicholls, G. (2015). Learning disabilities among Canadians aged 15 years and older. Ottawa, Ontario, Canada: Statistics Canada.

Brennan, S. (2009). Participation and Activity Limitation Survey 2006: Facts on learning limitations. Ottawa, Ontario, Canada: Statistics Canada. 
Brown, K. W., \& Ryan, R. M. (2003). The benefits of being present: Mindfulness and its role in psychological well-being. Journal of Personality and Social Psychology, 84(4), 822-848.

Bryan, T., Burstein, K., \& Ergul, C. (2004). The social-emotional side of learning disabilities: A science-based presentation of the state of the art. Learning Disabilities Quarterly, 27(1), 45-51.

Buonomo, I., Fiorilli, C., Geracia, M., \& Peped, A. (2017). Temperament and social-emotional difficulties: The dark side of learning disabilities. Journal of Genetic Psychology, 178(3), 193-206.

Büttner, G., \& Hasselhorn, M. (2011). Learning disabilities: Debates on definitions, causes, subtypes, and responses. International Journal of Disability, Development and Education, 58(1), 75-87.

Cameron, C. (Ed.) (2014). Disability Studies: A Student's Guide, 33-36. SAGE.

Castrodale, M. A. (2017). Critical disability studies and mad studies: Enabling new pedagogies in practice. Canadian Journal for the Study of Adult Education, 29(1), 49-66.

Cavendish, W. (2013). Identification of learning disabilities: Implications of proposed DSM-5 criteria for school-based assessment. Journal of Learning Disabilities 46(1), 52-57.

Chan, L.K.S., \& Dally, K. (2000). Review of literature. In W. Louden et al. (Eds.), Mapping the territory: Primary school students with learning difficulties in literacy and numeracy (Vol. 2, pp. 161-334). Canberra: Department of Education, Training and Youth Affairs.

Claxton, G. (1997). Hare brain, tortoise mind. London: Fourth Estate.

Cobigo, V., \& Stuart, H. (2010). Social inclusion and mental health. Current Opinion in Psychiatry, 23(5), 453-457.

Cortiella, C., \& Horowitz, S. H. (2014). The state of learning disabilities: Facts, trends and emerging issues. New York: National Center for Learning Disabilities.

D’Intino, J. S. (2017). Learning disabilities in Canada: Definitions and accommodations. Canadian Psychology, $58(3), 228-237$.

Ditrich, T. (2016). Buddhism between Asia and Europe: The concept of mindfulness through a historical lens. Asian Studies, 4(1), 197-213.

Fisher, R. (2006). Still thinking: The case for meditation with children. Thinking Skills and Creativity, 1(2), 146-151.

Fletcher, J. M., Morris, R., \& Lyon, G. R. (2003). Classification and definition of learning disabilities: An integrative perspective. In H. L. Swanson, K. R. Harris, \& S. Graham (Eds.), Handbook of learning disabilities (pp. 30-56). New York, NY: Guilford Press.

Geisler, F. C. M., Bechtoldt, M. N., Oberländer, N., \& Schacht-Jablonowsky, M. (2018). The benefits of a mindfulness exercise in a performance situation. Psychological Reports, 121(5), 853-876.

Goodley, D. (2001). 'Learning difficulties', the social model of disability and impairment: Challenging epistemologies. Disability \& Society, 16(2), 207-231.

Goodley, D. (2012). Dis/entangling critical disability studies. Disability \& Society, 28(5), 1-14.

Goodley, D., \& Runswick-Cole, K. (2013). The body as disability and possability: Theorizing the 'leaking, lacking and excessive' bodies of disabled children. Scandinavian Journal of Disability Research, 15(1), $1-19$.

Goodley, D., Lawthom, R., Liddiard, K., \& Runswick-Cole, K. (2017). Critical disability studies. In B. Gough (Ed.), The Palgrave Handbook of Critical Social Psychology (pp. 491-505). London: Palgrave.

Goodley, D., Lawthom, R., Liddiard, K., \& Runswick-Cole, K. (2019). Provocations for critical disability studies. Disability \& Society, 34(6), 972-997.

Gumpel, T. P. (2007). Are social competence difficulties caused by performance or acquisition deficits? the importance of self-regulatory mechanisms. Psychology in the Schools, 44(4), 351-372.

Hayes, L., Bach, P. A., \& Boyd, C. P. (2010). Psychological treatment for adolescent depression: Perspectives on the past, present, and future. Behaviour Change, 27(1), 1-18.

Haynes, J. (2002). Children as philosophers. London: Routledge.

Huppert, F. A., \& Johnson, D. M. (2010). A controlled trial of mindfulness training in schools: The importance of 
practice for an impact on well-being. Journal of Positive Psychology, 5(4), 264-274.

Integra. (2016). LDMH: A Handbook on Learning Disabilities and Mental Health. Retrieved from https://www.childdevelop.ca/sites/default/files/files/Sept\%2022\%20Integra\%20LDMH\%20Handbook\%202 016.pdf

Kabat-Zinn, J. (2003). Mindfulness-based interventions in context: Past, present, and future. Clinical Psychology: Science \& Practice, 10(2), 144-156.

Karmiris, M. (2016). Breaks and ruptures: Cripping the reading of Resistance. Canadian Journal of Disability Studies, 5(4), 204-222.

Kashani, J. H., \& Orvaschel, H. (1988). Anxiety disorders in mid-adolescence: A community sample. American Journal of Psychiatry, 145(8), 960-964.

Kavale, K., \& Mostert, M. (2004). Social skills interventions for individuals with learning disabilities. Learning Disability Quarterly, 27(1), 31-43.

Kimberlin, S. E. (2009). Political science theory and disability. Journal of Human Behaviour in the Social Environment, 19(1), 26-43.

Langer, E. J., \& Moldoveanu, M. (2000). The construct of mindfulness. Journal of Social Issues, 56(1), 1-9.

Learning Disabilities Association of Canada (2005). Official definition of learning disabilities. Retrieved December 6, 2018, from http://www.ldac-taac.ca/Defined/defined_new-e.asp

Martin, N. (2012). Disability identity-disability pride. Perspectives: Policy and Practice in Higher Education, 16(1), 14-18.

Mather, N., \& Gregg, N. (2006). Specific learning disabilities: Clarifying, not eliminating, a construct. Professional Psychology: Research and Practice, 37(1), 99-106.

Mendelson, T., Greenberg, M. T., Dariotis, J. K, Gould, L. F., Rhoades, B. L., \& Leaf, P. J. (2010). Feasibility and preliminary outcomes of a school-based mindfulness intervention for urban youth. Journal of Abnormal Child Psychology, 38(7), 985-994.

Mental Health Foundation. (2010). Be mindful report. The Mental Health Foundation. Retrieved from http://www.mentalhealth.org.uk/publications

Mrazek, M., Franklin, M., Phillips, D., Baird, B. M., \& Schooler, J. (2013). Mindfulness training improves working memory capacity and GRE performance while reducing mind wandering. Psychological Science, 24(5), 776-781.

Murphy, M., \& Donovan, S. (1999). The physical and psychological effects of meditation (2nd ed.). CA, Sausalito: Institute of Noetic Sciences.

Nagy, L. M., \& Baer, R. A. (2017). Mindfulness: “What should teachers of psychology know?" Teaching of Psychology, 44(4), 353-359.

Napoli, M., Krech, P. R., \& Holley, L. C. (2005). Mindfulness training for elementary school students: The attention academy. Journal of Applied School Psychology, 21(1), 99-125.

Nussbaum, M. (2003). Capabilities as fundamental entitlements: Sen and social justice. Feminist Economics, $9(2 / 3), 33-59$.

Paulesu, E., Danelli, L., \& Berlingeri, M. (2014). Reading the dyslexic brain: Multiple dysfunctional routes revealed by a new meta-analysis of PET and fMRI activation studies. Frontiers in Human Neuroscience, 8 , $1-20$.

Peña, E. V., Stapleton, L. D., \& Schaffer, L. M. (2016). Critical perspectives on disability identity. New Directions for Student Services, 1(154), 85-96.

Penney, C. G. (2018). Rethinking the concept of learning disability. Canadian Psychology, 59(2), 197-202.

Radford, J.P. (1994). Intellectual disability and the heritage of modernity. In M. H. Rioux, \& M. Bach (Eds.), Disability is not measles: New research paradigms in disability (pp. 9-27). North York. Ontario: Roeher Institute.

Reddy, C. R. (2011). From impairment to disability and beyond: Critical explorations in disability studies. Sociological Bulletin, 60(2), 287-306.

Rempel, K. D. (2012). Mindfulness for children and youth: A review of the literature with an argument for 
school-based implementation. Canadian Journal of Counselling \& Psychotherapy, 46(3), 201-220.

Robins, C. J., Keng, S. L., Ekblad, A. G., \& Brantley, J. G. (2012). Effects of mindfulness-based stress reduction on emotional experience and expression: A randomized controlled trial. Journal of Clinical Psychology, 68(1), 117-131.

Scruton, H., \& McNamara, J. (2014). Using motivational tactics to support children with reading disabilities. International Journal of Elementary Education, 3(4), 92-97.

Semple, R. J., Reid, E. F. G., \& Miller, L. (2005). Treating anxiety with mindfulness: An open trial of mindfulness training for anxious children. Journal of Cognitive Psychotherapy, 19(4), 379-392.

Sen, A. (2004). Disability and justice. Address to the World Bank Conference on Disability and Inclusive Development: Sharing, Learning, and Building Alliances. Washington, DC.

Shapiro, S., Carlson, L., Astin, J., \& Freedman, B. (2006). Mechanisms of mindfulness. Journal of Clinical Psychology, 62(3), 373-386.

Sharfi, K., \& Rosenblum, S. (2014). Activity and participation characteristics of adults with learning disabilities: A systematic review. PLOS ONE, 9(9), 1-8.

Shildrick, M. (2007). Contested pleasures: The sociopolitical economy of disability and sexuality. Sexuality Research and Social Policy, 4(1), 53-66.

Skues, J. L., \& Cunningham, E. G. (2011). A contemporary review of the definition, prevalence, identification and support of learning disabilities in Australian schools. Australian Journal of Learning Difficulties, 16(2), $159-180$.

Snow, C. E., Burns, M. S., \& Griffin, P. (1998). Preventing reading difficulties in young children. Washington, DC: National Academy Press.

Stichter, J. P., O'Connor, K. V., Herzog, M., Lierheime, K., \& McGhee, S. (2012). Social competence intervention for elementary students with Asperger's syndrome and high functioning autism. Journal of Autism \& Developmental Disorders, 42(3), 354-366.

Torgesen, J. K. (2004). Learning disabilities: An historical and conceptual overview. In B. Y. L. Wong (Ed.), Learning about learning disabilities (3rd ed., pp. 3-40). Amsterdam, The Netherlands: Elsevier.

United Nations Convention on the Rights of Persons with Disabilities (CRPD), adopted by the General Assembly on 13 December 2006, UN Doc. A/RES/61/106, 24 January 2007 (entered into force 3 May 2008).

United States Congress. Education for all handicapped children act of $1975.94^{\text {th }}$ U.S. Congress, Washington, D.C. 1975.

Vaughn, S., \& Haager, D. (1994). Social competence as a multifaceted construct: how do students with learning disabilities fare? Learning Disability Quarterly, 17(4), 253-266.

Wilson, A. M., Armstrong, C., Furrie, A., \& Walcot, E. (2009). The mental health of Canadians with self-reported learning disabilities. Journal of Learning Disabilities, 42(1), 24-40.

World Health Organization (WHO). International classification of functioning, disability and health (ICF), endorsed in May 2001, Res. WHA 54.21 of the 54th World Health Assembly (WHO 2001).

World Health Organization. (1980). International classification of impairments, disabilities and handicaps. Geneva: WHO.

\section{Copyrights}

Copyright for this article is retained by the author(s), with first publication rights granted to the journal.

This is an open-access article distributed under the terms and conditions of the Creative Commons Attribution license (http://creativecommons.org/licenses/by/4.0/). 